CARVALHO, A.M.; JUNQUEIRA, A.M.R.; VIEIRA, J.V.; BOTELHO, R. Análise sensorial de genótipos de cenoura cultivados em sistema orgânico e convencional. Horticultura Brasileira, Brasília, v.23, n.3, p.805-809, jul-set 2005.

\title{
Análise sensorial de genótipos de cenoura cultivados em sistema orgâni- co e convencional
}

\author{
Assis M. Carvalho'; Ana Maria R. Junqueira²; Jairo V. Vieira'; Raquel Botelho ${ }^{2}$ \\ ${ }^{1}$ Embrapa-Hortaliças, C. Postal 218, 70359-970 Brasília-DF; 2 UnB, C. Postal 4.508, 70910-970, Brasília-DF; E-mail: \\ assis@cnph.embrapa.br
}

\section{RESUMO}

Foi realizada análise sensorial em genótipos de cenoura Alvorada, Brasília RL, Brasília Bionatur, Kuronan, Nantes e Carandaí, produzidos em sistema orgânico e convencional no Distrito Federal. No teste de comparação pareada 1, foram utilizadas raízes de Alvorada, Brasília e Nantes servidas cruas para 33 consumidores na CEASA (DF). Não foi observada diferença estatística significativa entre as amostras para preferência do consumidor. No teste de comparação pareada 2, foi utilizada a cv. Brasília, cozida no vapor e servida a 24 pessoas de um edifício residencial, em Taguatinga (DF). As amostras provenientes do sistema orgânico foram preferidas pelos consumidores. Para o teste de ordenação 1 e 2 , doze pessoas não treinadas provaram amostras de Alvorada, Brasília RL, Brasília Bionatur, Kuronan, Nantes e Carandaí cozidas em água. Alvorada proveniente do sistema orgânico foi preferida pelos consumidores. No teste de comparação pareada 3, realizado em área aberta na Universidade de Brasília, foi utilizada a cv. Alvorada cozida em água e servida a 36 consumidores. Não foi observada diferença estatística significativa para preferência entre sistemas de cultivo. No teste de comparação pareada 4, realizado no restaurante da Embrapa Hortaliças, Alvorada cozida a vapor foi servida a 39 consumidores. Amostras provenientes do sistema orgânico foram preferidas pelos consumidores. Alvorada proveniente do sistema de cultivo orgânico e preparada no vapor foi preferida pelos consumidores em detrimento do mesmo material, cru ou cozido em água.

Palavras-chave: Daucus carota L., sistemas de cultivo, teste de comparação pareada, teste de ordenação, preferência do consumidor.

\begin{abstract}
Sensorial analysis of carrot genotypes grown under organic and conventional conditions

Sensorial analysis was carried out in carrot genotypes Alvorada, Brasília RL, Brasília Bionatur, Kuronan, Nantes and Carandaí, grown under organic and conventional systems in Distrito Federal, Brazil. For the paired comparison test 1, uncooked samples of 'Alvorada', 'Brasília' and 'Nantes' were given to 33 consumers. There was no statistical difference among genotypes or crop system for the consumer's preference. For the paired comparison test 2, vapor cooked samples of 'Brasília' were given to 24 consumers in a residence. Samples from the organic crop system were preferred by consumers. For the ranking tests 1 and 2, 12 persons not previously trained were selected to evaluate samples of 'Alvorada', 'Brasília RL', 'Brasília Bionatur', 'Kuronan', 'Nantes' and 'Carandaí' cooked in water. 'Alvorada' samples from the organic crop system were preferred by consumers. For the paired comparison test 3 , carried out at the University of Brasilia open area, samples of 'Alvorada' cooked in water were given to 36 consumers. There were no observed statistical differences between samples for consumer's preference. For the paired comparison test 4, carried out at Embrapa Hortaliça's restaurant, vapor cooked samples of 'Alvorada' were given to 39 persons. Samples from the organic crop system were preferred by consumers. Vapor cooked 'Alvorada' from the organic crop system was preferred by the consumers in comparison to 'Alvorada' uncooked or cooked in water.
\end{abstract}

Keywords: Daucus carota L., crop system, paired comparison test, ranking test, consumer's preference.

\section{(Recebido para publicação em 5 de outubro de 2004 e aceito em 25 de maio de 2005)}

A análise sensorial é utilizada para medir, analisar e interpretar reações às características dos alimentos e como elas são percebidas pelos sentidos da visão, olfato, gustação, tato e audição. O homem possui habilidade para comparar, diferenciar e quantificar atributos sensoriais. A análise sensorial aproveita esta habilidade para avaliar alimentos e bebidas, empregando metodologia adequada aos objetivos do estudo, bem como o tratamento estatístico adequado (FERREIRA, 1999).

Segundo Munhoz (1999) entre 1990 e 2000 existiam dois tipos de empresas: aquelas que implementariam o controle de qualidade e as que iriam falir por não implementá-lo. Em função disso é necessário que a indústria de produtos de consumo se interesse pelo campo de controle de qualidade. Este campo de estudo nasceu no Japão na década de 60 . Estes métodos foram rapidamente adaptados pelos demais países, depois de constatada a eficiência dos mesmos.

Os métodos sensoriais podem ser classificados em analíticos, que necessitam de equipe treinada para realizar avaliação objetiva, e, afetivos, onde os avaliadores não precisam de treinamento e podem expressar suas opiniões pessoais ou preferências. Os testes analíticos são classificados em a) teste de diferença: comparação pareada, triangular, duo-trio, ordenação e comparação múl- tipla e b) testes descritivos: perfil de sabor, perfil de textura e análise descritiva quantitativa. Os testes afetivos de preferência ou aceitação são classificados em: comparação pareada, ordenação, escala hedônica e escala do ideal (ABNT 1968, citado por FERREIRA, 1999).

Os testes que consideram uma resposta objetiva, como os discriminatórios, devem utilizar pessoas treinadas segundo a exigência do teste e o problema em foco. Os que utilizam resposta subjetiva podem ser realizados com pessoas não treinadas em técnicas de avaliação sensorial. Estes podem ser utilizados para avaliar a aceitabilidade e a preferência dos produtos (DE PENNA, 1999). 
Testes de comparação pareada são utilizados quando se deseja colocar um produto em competição direta com outro. $\mathrm{O}$ atributo deve ser especificado anteriormente. Este teste de preferência força o provador a escolher uma amostra em detrimento de outra, não indicando se o indivíduo gostou ou não do produto. A probabilidade de acertos no teste pareado é de 50\% (FERREIRA, 1999).

O teste de comparação pareada é utilizado quando duas amostras são fornecidas ao julgador para que seja determinada qual das duas possui o melhor atributo (doce, temperado, salgado, dentre outros). O julgador simplesmente tem que indicar qual das duas amostras ele prefere. Além disso, este teste pode também ser utilizado para medir a preferência (O’MAHONY, 1986).

No teste de ordenação três ou mais amostras são ordenadas por intensidade ou grau de algum atributo específico. Por exemplo: quatro amostras de iogurte são ordenadas pelo grau de acidez, ou cinco amostras de cereal ordenadas pela preferência. As amostras ordenadas recebem notas. A primeira amostra em ordem crescente de preferência recebe a nota 1 e a segunda 2 , assim por diante. Os números recebidos são somados por amostra e o resultado da soma total indica a ordem de preferência. Os testes de ordenação são rápidos e demandam relativamente pouco treinamento (MEILGAARD et al., 1991).

Segundo Darolt (2003), estudos sobre a qualidade organoléptica do produto orgânico avaliando sabor, aroma, acidez e palatabilidade são pouco conclusivos quando comparados ao cultivo convencional. Ele aponta que a falta de controle de inúmeras variáveis dificulta a pesquisa comparativa. Em pesquisas onde as variáveis foram mais controladas, o produto orgânico foi ligeiramente superior, entretanto os resultados não foram estatisticamente significativos.

A cenoura, muito apreciada na culinária, é um alimento utilizado em todas as etapas da vida do brasileiro. Ela possui baixo valor calórico, entretanto o teor de glicídios não pode ser desconsiderado. Eles são formados por açúcares livres, predominando sacarose sobre glicose e frutose, conferindo a esta raiz ótima sensibilidade gustativa.
Existem diferenças sensíveis na composição de açúcares nas partes de uma mesma raiz. O cilindro central, mais rico em fibra, é menos doce que a parte periférica (CHITARRA; CARVALHO, 1984).

Resende et al. (2003) avaliaram a qualidade sensorial da cenoura minimamente processada. Eles observaram que o tipo de corte em rodelas mantém o sabor e textura, característicos da cenoura, quando comparado ao corte ralado.

Ramana et al. (1992) estudaram a textura da cenoura em diversos tempos de cozimento. A análise sensorial evidenciou que ao incrementar o tempo de cozimento de 0 para 20 min., os painelistas atribuíram notas menores para a textura. Eles verificaram que uma variação no tempo de cozimento de 20 a 30 min. não possibilitou a separação das diferenças na textura.

Evers (1989) verificou que raízes de cenoura submetida à análise sensorial receberam nota 6,9 e 8,3 para gosto e textura, respectivamente, em escala de 1 (inaceitável) a 9 (excelente) em sistema de cultivo orgânico. Para o sistema de cultivo convencional, em ambos os atributos as notas foram 8,1. Após o armazenamento sob refrigeração, as raízes oriundas do sistema orgânico apresentaram notas para gosto e textura $25 \%$ e $18 \%$ superiores às não armazenadas.

Sant'ana (1995) estudou métodos de preparo de cenoura: ralada crua, cocção a vapor, cocção em água com pressão, cocção em água sem pressão e cocção em água e microondas. Ela concluiu que cenouras preparadas a vapor apresentaram menor umidade $(88 \%)$, maior teor de sólidos solúveis $(8,26 \%)$, menor lixiviação de sólidos solúveis $(2,82 \%)$ e maior teor de sólidos totais $(11,17 \%)$.

Borguini (2002) realizou análise sensorial em frutos de tomate e constatou que apenas para os atributos de sabor e aspecto geral houve diferença significativa ao nível de $5 \%$, entre tratamentos. $\mathrm{O}$ mesmo não ocorreu para aroma e sabor.

Tanto o tipo de corte como os métodos de cocção podem alterar a percepção dos consumidores frente a produtos da mesma cultivar e sistema de cultivo, sendo fundamental para determinar a preferência de um produto a outro, proceder testes diferenciados quanto a estes critérios.
Este trabalho teve como objetivo avaliar se consumidores seriam capazes de selecionar, em função da preferência, genótipos de cenouras conduzidos em sistema de orgânico e convencional.

\section{MATERIAL E MÉTODOS}

Foram utilizadas amostras de cenoura colhidas 95 dias após a semeadura. As raízes foram lavadas e padronizadas pelo comprimento, diâmetro e coloração. Aproximadamente 50 raízes comerciais de cada genótipo foram separadas para os testes sensoriais.

As amostras, depois de acondicionadas em sacos plásticos, foram identificadas e transportadas à temperatura ambiente $\left(24^{\circ} \mathrm{C}\right)$ em contentores plásticos ao laboratório de pós-colheita da Embrapa Hortaliças. Esta atividade durou cerca de duas horas. Posteriormente as raízes foram acondicionadas em câmara fria, a $4-5^{\circ} \mathrm{C}$, e cobertas com lona plástica para não sofrerem desidratação. As amostras foram preparadas no laboratório de Técnica Dietética da Faculdae de Nutrição da Universidade de Brasília e na unidade de produção do restaurante da Embrapa Hortaliças. Os testes sensoriais foram realizados de 28 de fevereiro a 10 de março de 2003.

Para cada teste foram utilizados genótipos oriundos dos sistemas de cultivo orgânico e convencional. 'Alvorada', 'Brasília' e 'Nantes' foram utilizados no teste de comparação pareada 1; 'Brasília' no teste de comparação pareada 2; 'Alvorada', 'Brasília' (Bionatur), 'Kuronan', 'Nantes' e 'Carandaí' nos testes de ordenação 1 e 2 e 'Alvorada' nos testes de comparação pareada 3 e 4 . Ao todo, foram realizados seis testes sensorias: quatro de comparação pareada e dois de ordenação. Foram utilizadas cenouras cruas, cozidas em água e a vapor. O tipo de teste, a data de aplicação, o local, o público e os procedimentos utilizados seguem:

\section{Teste de comparação pareada 1}

Realizado em 01/03/2003 das 9:00 às $11: 30 \mathrm{~h}$ junto aos consumidores que freqüentam a feira de produtores de hortaliças orgânicas da Associação de Agricultura Ecológica (AGE) de Brasília, localizada no estacionamento da CEASA-DF. Este teste teve como obje- 
tivo verificar se os consumidores preferiam amostras de cenouras proveniente do sistema de cultivo orgânico ou do convencional. A amostra foi composta de duas raízes comerciais de cada parcela, totalizando 10 raízes. Após a retirada da casca e das extremidades as raízes foram fatiadas em dimensões homogêneas, aproximadamente $0,5 \mathrm{~cm}$ de espessura e $3 \mathrm{~cm}$ de diâmetro. Foram servidas, seqüencialmente, duas amostras cruas de cada genótipo aos provadores. Os avaliadores foram abordados, ao acaso, entre o público freqüentador da feira, onde era explicada a metodologia do teste. Foram instaladas duas cabinas de isopor, sobre mesas ao ar livre, na área de maior movimento de pessoas. Foi fornecido para cada avaliador bandeja de papel contendo copo plástico descartável, água mineral fria, prato plástico descartável com cinco rodelas de cenoura, palitos e guardanapo de papel. Foram solicitadas a identificação do avaliador e a data. No formulário o provador encontrou explicações sobre a quantidade de amostras e solicitação para que provasse cada par de amostras da esquerda para a direita e circulasse aquela de "melhor sabor" entre os três pares fornecidos. Espaços adicionais no formulário foram fornecidos para o provador fazer comentários. Foi solicitado ao provador que enxaguasse a boca após a degustação do conteúdo de cada prato. Trinta e três pessoas participaram dos testes. Todas receberam 3 pares de amostras codificadas com 4 dígitos, metade na ordem $\mathrm{AB}$ e metade na ordem BA.

\section{Teste de comparação pareada 2}

Realizado em 05/03/2003 das 9 às $11 \mathrm{~h}$ e das 17 às $19 \mathrm{~h}$ entre moradores de um edifício, localizado em Taguatinga (DF). Cada amostra foi composta de dez raízes comerciais. Após a retirada da casca e extremidades as raízes foram fatiadas em dimensões homogêneas de $0,5 \mathrm{~cm}$ de espessura por 3 $\mathrm{cm}$ de diâmetro. Foram separadas amostras de 200 g. O método de cocção escolhido foi a vapor convencional. As raízes foram cozidas por $25 \mathrm{~min}$. Os consumidores foram abordados, ao acaso, em suas residências, onde foi explicada a metodologia do teste. $\mathrm{O}$ teste foi realizado na mesa de refeições de cada provador. Os materiais fornecidos foram semelhantes ao descrito no teste anterior. Vinte e quatro pessoas participaram do teste. Todas receberam um par de amostras codificado com 4 dígitos, metade na ordem $\mathrm{AB}$ e metade na ordem BA.

\section{Teste de ordenação 1 e 2}

Realizado nos dias 6 e 7 de março de 2003, às 15 h, com doze pessoas previamente selecionadas. Este teste foi realizado em laboratório da UnB em sala iluminada. Foram utilizados genótipos oriundos do sistema orgânico e convencional nos dias 6 e 7, respectivamente. Foram selecionadas 10 raízes, divididas em 3 partes iguais e a parte intermediária constituiu a amostra composta. A parte selecionada foi fatiada, separadas $200 \mathrm{~g}$ e, aproximadamente, $20 \mathrm{~g}$ para cada provador. A amostra foi colocada em panela de alumínio e levada ao fogo em fogão elétrico para cozimento até o ponto "ao dente" (cerca de meia hora) em solução de $1,5 \%$ de sal e $2 \%$ de açúcar. Os provadores sentaram em cadeiras e utilizaram cabinas colocadas sobre mesa de fórmica branca. As amostras foram servidas aos provadores em bandejas de papel com pratos de plástico e talheres descartáveis, água fria e porta lixo. Foi solicitado aos 12 provadores que, ao degustarem as seis amostras da esquerda para a direita, ordenasse-as na ficha fornecida, de forma crescente, da pior para a melhor, em função da "sua preferência".

\section{Teste de comparação pareada 3}

Realizado no dia 07 de março de 2003 das 10:30 às 12:00 h em via pública, na entrada da UnB. O preparo da amostra foi similar ao procedimento descrito anteriormente. Os provadores foram abordados ao acaso e foi explicada a metodologia do teste. Trinta e seis pessoas participaram do teste. Todas receberam um par de amostras codificado, com 4 dígitos, metade na ordem $\mathrm{AB}$ e metade na ordem $\mathrm{BA}$.

\section{Teste de comparação pareada 4}

Realizado no dia 10 de março de 2003 das 11:20 às 12:40 h no restaurante da Embrapa Hortaliças. O método de cocção escolhido foi a vapor convencional. A cocção de cada amostra foi realizada por $20 \mathrm{~min}$. Os provadores foram abordados ao acaso dentre os clientes do restaurante. Trinta e nove pessoas participaram do teste. Todas receberam um par de amostras codificado, com 4 dígitos, metade na ordem $\mathrm{AB}$ e metade na ordem BA.

Os resultados foram submetidos à análise de variância e as médias comparadas pelo teste de Tukey, ao nível de $5 \%$ de probabilidade, segundo metodologia proposta por Ferreira (2000) e Ferreira (1999).

\section{RESULTADOS E DISCUSSÃO}

No teste de comparação pareada 1 , foram obtidas 33 respostas para cada cultivar. Para a cv. Brasília, uma resposta foi considerada nula em função de marcação dupla. Das 32 respostas válidas, 18 provadores preferiram a amostra $\mathrm{A} \mathrm{e}$ 14 a B. Para a cv. Kuronan foram verificadas duas respostas nulas em função de não marcação. Das 31 respostas válidas 18 provadores preferiram a amostra A e 13 a B. Já para a Nantes, cinco foram nulas em função de não marcação ou marcação dupla. Das 28 respostas válidas 14 provadores preferiram a amostra A e 14 a B.

Em nenhum dos genótipos avaliados foi observada diferença estatística significativa entre as amostras, considerando os níveis de significância de $0,1 \%$; $1 \%$; $5 \%$ e $10 \%$. Não foi possível separar os genótipos e sistemas de cultivo de maior preferência entre os provadores.

Cenouras servidas cruas podem influenciar a preferência dos provadores Sant' ana (1995), dificultando que amostras provenientes de sistema de cultivo diferentes sejam separadas pelo sabor ou textura (EVERS, 1989).

Para o teste de comparação pareada 2 , todas as respostas foram consideradas válidas. Desse total, 17 provadores preferiram a amostra A e 7 a B, indicando que os entrevistados deram preferência à cenoura proveniente do sistema de cultivo orgânico (nível de significância de $10 \%$ ).

Segundo Sant' ana (1995) a cenoura preparada a vapor pode eliminar substâncias voláteis indesejáveis, acentuando o sabor e facilitando a escolha do 
Tabela 1. Teste de ordenação de seis genótipos de cenoura $A=$ Alvorada, $B=$ Brasília RL, $C=$ Brasília (Bionatur), $\mathrm{D}=$ Kuronan, $\mathrm{E}=$ Nantes 3 Tip Top e $\mathrm{F}=$ Carandaí, provenientes do sistema de cultivo orgânico, submetido a doze provadores não treinados. Brasília, UnB, 2003.

\begin{tabular}{ccccccc}
\hline \multirow{2}{*}{ Provador } & \multicolumn{6}{c}{ Amostras dos genótipos de cenoura do sistema orgânico } \\
\cline { 2 - 7 } & A & B & C & D & E & F \\
\hline 1 & $1^{*}$ & 5 & 4 & 3 & 6 & 2 \\
2 & 1 & 6 & 2 & 3 & 4 & 5 \\
3 & 1 & 6 & 2 & 5 & 3 & 4 \\
4 & 1 & 5 & 6 & 2 & 4 & 3 \\
5 & 1 & 4 & 5 & 3 & 6 & 2 \\
6 & 6 & 4 & 1 & 2 & 3 & 5 \\
7 & 3 & 5 & 6 & 2 & 4 & 1 \\
8 & 6 & 1 & 5 & 3 & 4 & 2 \\
9 & 1 & 2 & 3 & 5 & 6 & 4 \\
10 & 2 & 3 & 5 & 1 & 6 & 4 \\
11 & 5 & 2 & 4 & 1 & 6 & 3 \\
12 & 2 & 3 & 4 & 5 & 6 & 1 \\
\hline Total & 30 & 46 & 47 & 35 & 58 & 36 \\
\hline
\end{tabular}

*As notas 1 e 6 correspondem às de maior e menor preferência pelos consumidores, respectivamente.

Tabela 2. Teste de ordenação de seis genótipos de cenoura $\mathrm{A}=$ Alvorada, $\mathrm{B}=$ Brasília RL, $\mathrm{C}=$ Brasília (Bionatur), $\mathrm{D}=$ Kuronan, $\mathrm{E}=$ Nantes 3 Tip Top e $\mathrm{F}=$ Carandaí, provenientes do sistema de cultivo convencional, submetido a doze provadores não treinados. Brasília, UnB, 2003.

\begin{tabular}{cllllll}
\hline \multirow{2}{*}{ Provador } & \multicolumn{6}{c}{ Amostras dos genótipos de cenoura do sistema convencional } \\
\cline { 2 - 7 } & A & B & C & D & E & F \\
\hline 1 & $1^{*}$ & 3 & 2 & 4 & 6 & 5 \\
2 & 2 & 3 & 5 & 4 & 6 & 1 \\
3 & 1 & 6 & 4 & 5 & 3 & 2 \\
4 & 5 & 6 & 2 & 1 & 3 & 4 \\
5 & 3 & 1 & 4 & 2 & 5 & 6 \\
6 & 1 & 6 & 4 & 5 & 2 & 3 \\
7 & 6 & 2 & 5 & 3 & 1 & 4 \\
8 & 1 & 6 & 2 & 3 & 4 & 5 \\
9 & 2 & 1 & 4 & 5 & 6 & 3 \\
10 & 3 & 6 & 4 & 5 & 1 & 2 \\
11 & 2 & 5 & 1 & 4 & 6 & 3 \\
12 & 5 & 3 & 4 & 2 & 6 & 1 \\
\hline Total & 32 & 48 & 41 & 43 & 49 & 39 \\
\hline
\end{tabular}

*As notas 1 e 6 correspondem às de maior e menor preferência pelos consumidores, respectivamente.

provador. Outros fatores como o ambiente familiar e a tranqüilidade do provador podem, também, ter contribuído para que o teste alcançasse o nível de significância observado.

Nos testes de ordenação 1 e 2 objetivou-se determinar a ordem de preferência entre as amostras de genótipos: Os resultados obtidos em formulários foram organizados em um quadro de ordenação e preferência segundo a metodologia proposta por (FERREIRA, 1999). A diferença mínima entre totais de ordenação para estabelecer diferença significativa de preferência entre amostras, ao nível de $5 \%$ de significância, é de 27 pontos, segundo este autor.

Para cenoura proveniente do sistema orgânico, os resultados indicam a existência de três grupos distintos em relação à aceitabilidade: (A = 'Alvorada'; D = 'Kuronan' e F = 'Carandaí'), (B = 'Brasília' e C = 'Brasília Bionatur') e (E = 'Nantes 3 Tip Top'). Entretanto, o genótipo mais preferido foi o $\mathrm{A}=\mathrm{Al}$ - vorada, pois foi o único que atingiu e superou (27 pontos) a diferença mínima de significância ao nível de 5\% (Tabela 1).

Este genótipo foi disponibilizado pela pesquisa ao agronegócio de hortaliças pelas características de alta resistência à queima-das-folhas (similar à cultivar Brasília); alto teor de carotenóides totais (cerca de 35\% superior ao das cultivares do grupo Brasília); alta resistência aos nematóides formadores de galhas nas raízes; produtividade de 30-35 t de raízes comerciais/ha nas principais regiões produtoras; formato de raiz predominantemente cilíndrico, com coloração externa alaranjada intensa; coloração interna alaranjada e uniformemente distribuída entre o xilema e floema (ausência de "miolo branco") e baixa incidência de ombro verde (VIEIRA et al., 2000).

Para cenoura proveniente do sistema convencional nenhum genótipo atingiu a diferença mínima de significância ao nível de $5 \%$ de probabilidade (Tabela 2). Evers (1999) demonstrou que o sistema de cultivo convencional pode exercer influência na qualidade sensorial das amostras. Porém, a menor nota total (32) foi atribuída à cv. Alvorada, evidenciando sua preferência pelos provadores independe do sistema de cultivo.

O teste de comparação pareada 3 procurou determinar se alunos, funcionários, professores e visitantes da UnB preferiam amostras de cenoura da $\mathrm{cv}$. Alvorada, provenientes do sistema orgânico ou convencional, cozidas em água. Das 36 respostas obtidas, uma foi considerada nula devido a rasuras. Das respostas válidas 18 provadores preferiram a amostra A e 17 a B. Apesar de a amostra Alvorada, proveniente do sistema de cultivo orgânico ser a preferida, não foi alcançado o número suficiente de respostas para observação de diferença estatística significativa entre as amostras.

Foi realizado o teste de comparação pareada 4, com o objetivo de verificar a preferência dos clientes, do restaurante da Embrapa Hortaliças, com amostras de cenouras preparadas a vapor da cv. Alvorada, provenientes do sistema orgânico e convencional. Foram obtidas 
39 respostas válidas. Deste total, 30 provadores preferiram a amostra A (sistema orgânico) e, 9 B (sistema convencional). Foi alcançado o número de respostas suficiente para observação de diferença estatística significativa entre as amostras (nível de significância de $1 \%)$. Houve, portanto, preferência pelas amostras do genótipo Alvorada provenientes do sistema de cultivo orgânico e cozidas a vapor.

Conclui-se então que nos testes de ordenação, 'Alvorada' proveniente do sistema de cultivo orgânico, cozida em água, foi preferida pelos consumidores. A mesma cultivar, submetida ao teste de comparação pareada, proveniente do sistema de cultivo orgânico e preparada a vapor foi preferida pelos provadores em detrimento das amostras, do mesmo material, servida crua ou após cozimento em água.

\section{LITERATURA CITADA}

BORGUINI, R.G. Tomate (Lycopersicum esculentum Mill) orgânico: o conteúdo nutricional e a opinião dos consumidores. 2002. 110 f. (Tese mestrado) - ESALQ, USP, Piracicaba.

CHITARRA, M.I.F.; CARVALHO, V.D. Cenou- ra: qualidade e industrialização. Informe Agropecuário, Belo Horizonte, v.10, n.120, p.7375. 1984.

DAROLT, M.R. Comparação da Qualidade do Alimento Orgânico com o Convencional. In: STRIGHETA, P.C.; MUNIZ, J.N. Alimentos Orgânicos: Produção, Tecnologia e Certificação.1 ed. Viçosa: Universidade Federal de Viçosa - UFV, 2003, p.289-312.

DE PENNA, E.W. Metodos sensoriales y sus aplicaciones. Avances en análisis sensorial. ALMEIDA, T.C.A.; HOUGH, G.;DAMÁSIO, M.H.; da SILVA. M.A.A.P. (Orgs). CYTED. São Paulo. p.13-22. 1999.

EVERS, A.M. The role of fertilization practices in the yield and quality of carrot (Daucus carota L.). Journal of Agricultural Science in Finland. Maataloustieteellinen Aikakauskirja. v. 61, n.4 329-360, 1989

FERREIRA, P.V. Estatística experimental aplicada a Agronomia. 3.ed. Maceió: EDUFAL, 2000 $422 \mathrm{p}$.

FERREIRA, V.L.P. Análise sensorial: testes discriminativos e afetivos. São Paulo: PROFÍQUA; CAMPINAS; SBCTA. 1999. 109 p (Manual. Série Qualidade).

MEILGAARD, M.; CIVILLE, G.V.; CARR, B.T Sensory evaluation techniques. $2^{\mathrm{a}} \mathrm{ed}$. Boca Raton. 1991. 354 p.

MUNHOZ, A.M. Análisis sensorial en el control de calidad. Avances en análisis sensorial. ALMEIDA, T.C.A.; HOUGH, G.;DAMÁSIO, M.H.; SILVA, M.A.A.P. (Orgs). CYTED. São Paulo. p.83-87. 1999.

O'MAHONY, M. Sensory evaluation of food.
Estatistical methods and procedures. Davis, Califórnia. 1986. 487 p.

RAMANA, S.V.; WRIGHT, C.J.; TAYLOR, A.J. Measurement of Firmness in Carrot Tissue during Cooking using Dynamic, Static and Sensory Test. Journal of The Science of Food and Agriculture. Great Britain. v.60, n.3, p.369-375, 1992.

RESENDE, J.M.; COELHO, S.F.A.; CASTRO, E.C.; JÚNIOR, O.J.S.; NASCIMENTO, T.; BENEDETTI, B.C. Avaliação sensorial de cenoura minimamente processada em diferentes cortes. Horticultura Brasileira, Brasília, v.21, n.2, p 381, 2003. Resumos do $43^{\circ}$ Congresso Brasileiro de Olericultura. Suplemento 1.

SANT'ANA, H.M.P. Efeito do método de preparo sobre a estabilidade de carotenóides em cenoura (Daucus carota L.). 1995. 115 f. (Tese Mestrado) - Universidade Federal de Viçosa, MG. VIEIRA, J.V.; RITSCHEL, P.S. CHARCHAR, J.M. LANA, M.M.; LIMA, D.B.; LOPES, C.A.; MOITA, A.M. Alvorada: nova cultivar de cenoura para plantio de verão. Brasília, Embrapa Hortaliças. 2000. Folder. 